\title{
Active protection of work area against explosion of dust-gas mixture
}

\author{
Zbigniew Szkudlarek ${ }^{1}$ (1) $\cdot$ Sebastian Janas $^{1}$
}

Received: 11 March 2020/Revised: 2 June 2020/Accepted: 1 December 2020/Published online: 1 January 2021

(C) The Author(s) 2021

\begin{abstract}
Potentially explosive atmosphere can occur not only in the production systems of the food, energy, chemical and petrochemical industries but also in the production processes of the mining industry. Gases, vapours, mists and dusts arise can escape in an uncontrolled way during production, processing, transportation and storage of flammable substances. In combination with oxygen, they create explosive atmospheres that, if ignited, lead to an explosion causing catastrophic damage to people's lives and property. To protect against the results of hazardous dust-gas mixtures explosions in a confined work space, where employees can stay, various control and protection mechanisms are used in the form of an active explosion-proof system. The article presents the results of tests on an active system for limiting the effects of ignition of gas and/or dust based on a highly efficient explosion suppression system-equipped with an ignition detection system, high-pressure fire extinguisher and a power supply and trigger system. Smokeless powder was used as the explosive charge and sodium bicarbonate as the suppressive material. Tests of the effectiveness of the active explosion suppression system were carried out on two devices: a small-size dry dust collector and a zone extinguishing system adapted for direct explosion suppression in closed working spaces. In both cases, the explosion suppression process took place through the action of extinguishing powder blown out of the fire extinguisher after membrane perforation by compressed combustion products.
\end{abstract}

Keywords Gas hazard $\cdot$ Explosive dust $\cdot$ Suppression of explosion $\cdot$ Safety of work area

\section{Introduction}

In many industries, such as the mining, food, chemical, textile or pharmaceutical industries, there are flammable dusts and gases that are either a raw material for further processing, or occur as a final product or unwanted byproduct. In many installations, these substances occur in the form of a dust-air mixture, but it often happens that due to the imperfect operation of ventilation devices or for other reasons, they remain in the layer and pose a very serious explosion hazard. A safe and trouble-free

\section{Zbigniew Szkudlarek}

zszkudlarek@komag.eu

1 KOMAG Institute of Mining Technology, 44-101 Gliwice, Poland production process is an important goal for ensuring people's safety and a clean work environment. In industrial plants, explosions occur inside tanks, process systems or corridors, from which they can spread outside the facility. Explosion protection is often seen in combination with gases, however dust or a mixture of these with gases can also create an explosive atmosphere. The best way to avoid serious damage to industrial facilities is to accurately locate the hazard and then stop the explosion inside the hazardous area.

The duration of a typical dust explosion inside a tank with a volume of several cubic meters is several dozen to several hundred milliseconds. The explosion should be suppressed within a dozen or so milliseconds of its initiation, otherwise the pressure inside the tank may increase excessively. To meet this rather stringent requirement, the 
extinguishing agent must be sprayed at a high speed, on the order of $100 \mathrm{~m} / \mathrm{s}$. This task is to be fulfilled by active systems suppressing the explosion of dust and mixtures with hazardous gases, in which extinguishing powders or water are used. They were designed to ensure early detection of a developing explosion and its immediate suppression.

The experimental research conducted by Moore (1996) allows determining the effective extinguishing concentration for extinguishing agents in the form of halons and water as well as for selected powders.

Active HRD suppression system in a confined space was the subject of research work (Lesiak et al. 2019). The test stand was designed and manufactured to meet the assumptions of the PN-EN 14034 series of standards. The testing device consisted of a closed chamber similar to a sphere with a volume of $1 \mathrm{~m}^{3}$ and ignition systems, creation of a dust-air atmosphere, detection of pressure changes. Inside the sphere, a dust-air mixture of a certain concentration was obtained in a reproducible manner. The stand was equipped with a dust explosion suppression system containing: a $5 \mathrm{dm}^{3}$ fire extinguisher tank containing extinguishing material under pressure, a dispersion nozzle and an explosion detection system. The operation of the extinguishing system was based on the early detection of a change in the pressure of the explosion of a dust-air mixture, the processing of the signal and the release of the extinguishing agent into the interior of the apparatus in order to interrupt the explosion process at the earliest possible stage of its development. Based on the conducted experiments, it was found that the HRD system effectively stops the explosive combustion for dust with $K_{\mathrm{st}} \leq 100 \mathrm{bar} \mathrm{m} / \mathrm{s}$. For tested potato starch dust, the system significantly reduces the explosion pressure to an acceptable value. The system was also characterized by a short response time, and the discharge of extinguishing material occurs in an acceptable time below $100 \mathrm{~ms}$.

Späth et al. (2011) presented the benefits of using the ExploSpot active explosion suppression system in relation to passive barriers, which is to be an important element for state-of-the-art safety in hard coal mines. It is based on an integrated modular structure allowing it to be used in various configurations. Test device tests confirmed its effectiveness in suppressing gas and coal dust explosions in various required environments.

du Plessis (2015) tested the ExploSpot active barrier system based on the sensors that activated the outflow of high-pressure suppressing material, when an explosion was detected. It can be concluded from the tests that the system successfully stopped flame propagation in the case of methane explosion as well as methane and coal dust when ammonium phosphate powder was used as the extinguishing material. The active barrier effectively suppressed spreading the methane flames approaching the barrier at flame speeds ranging from 24.4 to $62.2 \mathrm{~m} / \mathrm{s}$. The maximum flame distance measured was $11 \mathrm{~m}$, compared to over $80 \mathrm{~m}$ without barrier. As the flame did not move beyond the barrier, it could be concluded that no coal dust was involved in the explosion.

Active explosion suppression systems tested by Lesiak et al. (2019) as well as Späth et al. (2011) and du Plessis (2015) are based on the structure of the fire extinguisher tank in which the extinguishing material was kept at a certain high pressure (50-80 bar).

Oleszczak et al. (2007), Klemens et al. (2007) and Gieras and Klemens (2012) studied the effectiveness of suppression of an explosion initiated by a mixture of corn starch with air pneumatically dispersed inside a $1.3 \mathrm{~m}^{3}$ test chamber. The suppression system was composed of an optical detection system and a steel container, in which explosives were used as a gas generator to perforate the membrane closing the container, as well as to disperse the suppressive material from the container into a protected volume. Water and sodium bicarbonate were used as explosion suppressive material. Two types of gas generators were used in tests with water as the suppressive material: smokeless powder or pyrotechnic charge. In the sodium bicarbonate tests, a smokeless powder charge was used as the gas generator. The results of the tests confirmed that the suppression system is effective in suppressing dust and gas explosions regarding such parameters as: explosion pressure, explosion pressure increase rate and deflagration index. For the assumed levels of the photodiode trigger signal: $0.3 \mathrm{~V}, 0.6 \mathrm{~V}$ and $1.0 \mathrm{~V}$ in the case of suppression of dust explosion, the obtained explosion pressures were as follows: $0.035,0.055$ and 0.24 bar, respectively, while in the case of gas explosion the explosion pressures were: 0.06, 0.075 and 0.21 bar, respectively. Based on the pressure histories recorded in the fire extinguisher during an explosion inside its explosive charge, it was found that the estimated time to empty the fire extinguisher from the extinguishing material was from 25 to $30 \mathrm{~ms}$-which allowed effective suppression of even a very strong explosion. The range of pressures in the fire extinguisher during the explosion of the explosive charge for the rapid and accurate opening of the membrane, i.e. without detached fragments, was from 130 to 190 bar.

Wang et al. (2017) used composite powders $\mathrm{NaHCO}_{3} /$ RM to suppress explosions of an air-methane mixture with a concentration of $9.5 \% \mathrm{CH}_{4}$ in a $20 \mathrm{dm}^{3}$ spherical chamber. The $\mathrm{NaHCO}_{3}$ inhibitor accounted for $35 \%$ of the volume of the composite powder. With respect to pure RM or $\mathrm{NaHCO}_{3}$ powders, it showed a significant composite inhibitory effect manifested in a $44.9 \%$ decrease in the maximum explosion pressure, a decrease in the maximum 
pressure increase rate by $96.3 \%$, and a decrease in the peak delay time by $366.7 \%$.

Pei et al. $(2018,2019)$ presented experimental studies using $\mathrm{N}_{2}$ and $\mathrm{CO}_{2}$ and ultra-fine water mist to suppress flame propagation characteristics in the initial explosion phase of a mixture of air and methane with a concentration of $9.5 \%$ in a constant volume chamber. In research, he stated that when the $\mathrm{CO}_{2}$ volume share is greater than $14 \%$, the flame disappears. This means that the right amount of $\mathrm{CO}_{2}$ better inhibits flame self-acceleration when a mixture of air and methane explodes. Using a two-component water mist with $\mathrm{N}_{2}$, the average flame speed decreased by $29.54 \%$ at a pressure of 2 bar and a spraying time of $1 \mathrm{~s}$, while using a two-component water mist with $\mathrm{CO}_{2}$, the average flame speed decreased by $34.58 \%$ at a pressure of 3 bar and spraying time $1 \mathrm{~s}$. The effect of $\mathrm{N}_{2}$ and $\mathrm{CO}_{2}$ on reducing the overpressure of methane explosion is also evident. Compared with two liquid water mists without inert gas, the peak of explosion overpressure was reduced by $31.71 \%$ using $\mathrm{N}_{2}$, at 2 bar pressure and spraying time of $3 \mathrm{~s}$, and the pressure of the explosion using $\mathrm{CO}_{2}$ was reduced by $51.44 \%$ aqueous at 4 bar pressure and spraying time $3 \mathrm{~s}$.

In turn, Cao et al (2015) studied the effect of suppression of ultra-fine mists with a $\mathrm{NaCl}$ solution on the explosions of an air-methane mixture at methane concentrations of $6.5 \%, 8 \%, 9.5 \%, 11 \%$ and $13.5 \%$. He determined that when the amount of fog reached $74.08 \mathrm{~g} / \mathrm{m}^{3}$ and $37.04 \mathrm{~g} / \mathrm{m}^{3}$, for methane concentrations of $6.5 \%$ and $13.5 \%$, respectively, the flames of methane explosions were completely suppressed. All results indicate that the addition of $\mathrm{NaCl}$ to the ultra-fine mist of pure water can improve the suppression effect of methane explosions.

Bochorishvili etal. (2015) tested a new methane explosion suppression system in the $2.2 \mathrm{~m} \times 2.2 \mathrm{~m}$ cross-section pavement, in which a water mist with a drop size of 25-400 $\mathrm{mm}$ was used as the damping material. The activation time of the suppression system was $11 \mathrm{~ms}$ from the moment of explosion, and the reduction of shock wave pressure decreased by $1.80-2.98$ times. The minimum overpressure activating the damping system was $12 \mathrm{kPa}$.

This paper presents pilot tests on the efficiency of suppression of explosions caused by an air-dust and airmethane mixture. For this purpose, a small dry dust collector and a zonal extinguishing system was used to suppress explosions in large closed working areas. Highperformance explosion suppression system based on a high-pressure extinguisher was used in the tests. Sodium bicarbonate was the explosion suppressant. The fire extinguisher has thanks of innovative design in which there is no pressure inside, when there is no trigger signal. Only the signal from the sensor detecting the explosion activates the powder charge inside the fire extinguisher together with suppressing powder and pushes it into the protected area. Extinguishing powder was used instead of water for the rational reasons and for better suppression efficiency in the case of air-methane mixture explosions.

To protect the internal space of the dry dust collector, three fire extinguishers with a capacity of $2 \mathrm{dm}^{3}$ each were used. This amount of damping powder was sufficient to effectively protect the space filled with explosive dust. The explosion pressure increase inside it did not exceed 0.14 bar and the fire extinguishing system was activated within $4 \mathrm{~ms}$. The increase in pressure did not damage the dust collector structure.

The tested zone suppression system allows to stop the explosion of an air-methane mixture for a methane concentration of up to $5 \%$, provided that the concentration of extinguishing powder is $\min .0 .7 \mathrm{~kg} / \mathrm{m}^{3}$ of the protected volume.

\section{Dust tests of high-pressure extinguisher}

High pressure extinguishers (Fig. 1) with a capacity of 2 and $10 \mathrm{dm}^{3}$ were used for dust tests, which were carried out in chambers with a capacity of $1.3 \mathrm{~m}^{3}$ and $5 \mathrm{~m}^{3}$, respectively. The comparative criterion was to obtain the right pressure inside the fire extinguisher-the optimum range was 120 to $180 \mathrm{bar}$, which, when the diaphragm was properly opened, allowed to obtain a sufficiently short emptying time of the fire extinguisher below $30 \mathrm{~ms}$ and the suppressive explosion pressure in the protected space of less than 0.4 bar (Szkudlarek et al. 2014).

First, a $2 \mathrm{dm}^{3}$ fire extinguisher was tested, which was an equipment for protection of small spaces, e.g. the space of a dry dust collector. Due to the possibility of operating such a dust collector in areas threatened by dust explosion hazard, it becomes expedient to protect the dust collector
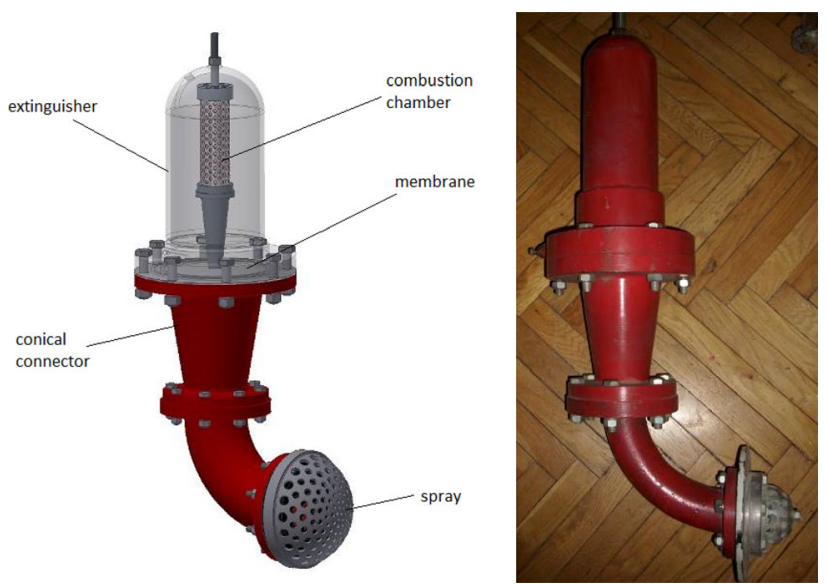

Fig. 1 High-pressure fire extinguisher of capacity $2 \mathrm{dm}^{3}$ 

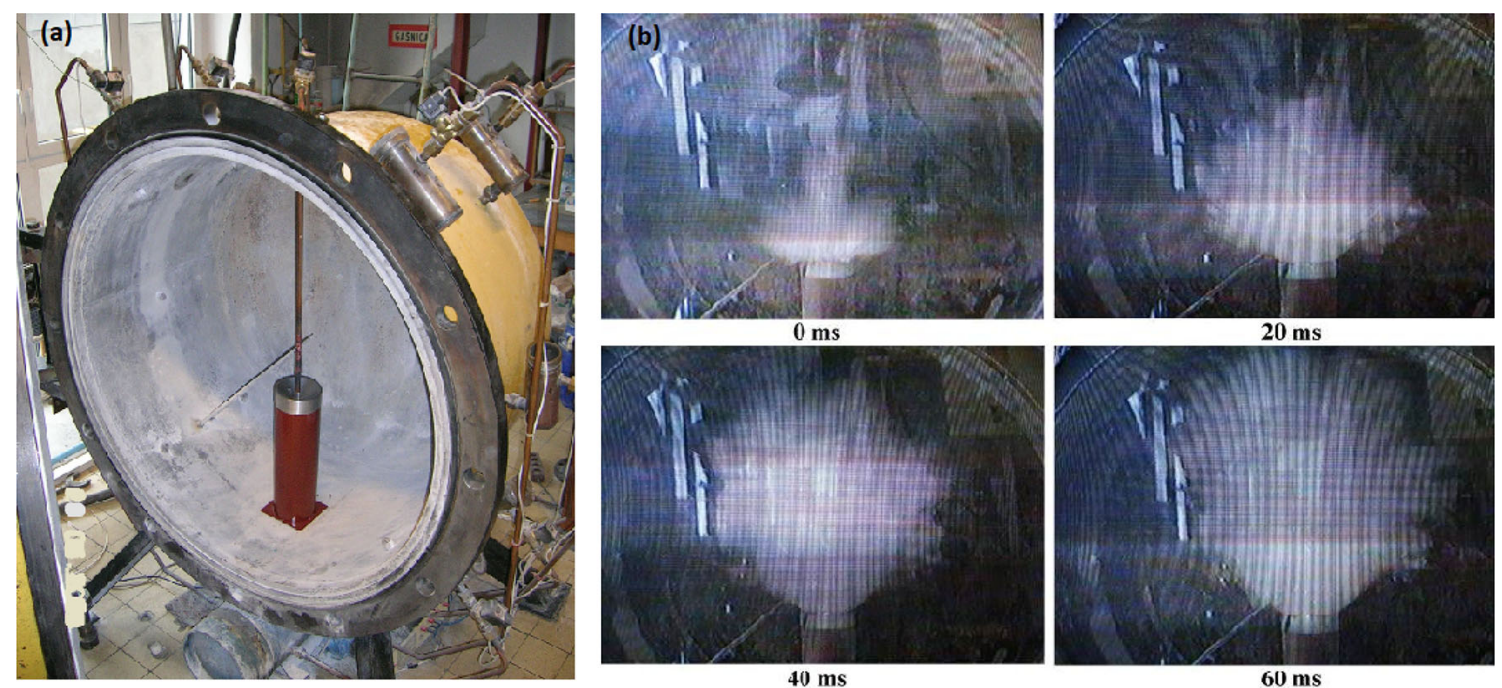

Fig. 2 a View of a $1.3 \mathrm{~m}^{3}$ test chamber adapted for testing of the spreading system in a dry bag dust collector and $\mathbf{b}$ an example of the process of spreading the combustible dust in a $1.3 \mathrm{~m}^{3}$ chamber

Table 1 Tested parameters of spreading the explosive dust

\begin{tabular}{|c|c|c|c|c|c|c|c|c|}
\hline Test No. & 1 & 2 & 3 & 4 & 5 & 6 & 7 & 8 \\
\hline $\begin{array}{l}\text { Spreading } \\
\text { time }(\mathrm{ms})\end{array}$ & 250 & 150 & 150 & 250 & 150 & 100 & 150 & 200 \\
\hline $\begin{array}{l}\text { Spreading } \\
\text { pressure } \\
\text { (bar) }\end{array}$ & 6 & 6 & 8 & 8 & 10 & 10 & 8 & 8 \\
\hline $\begin{array}{l}\text { Dust weight } \\
\text { (g) }\end{array}$ & 150 & 130 & 130 & 130 & 130 & 130 & 160 & 160 \\
\hline $\begin{array}{l}\text { Observation } \\
\text { results }\end{array}$ & $\begin{array}{l}\text { Powder fully } \\
\text { evenly } \\
\text { spread }\end{array}$ & $\begin{array}{l}\text { Small amount of } \\
\text { powder not } \\
\text { spread }\end{array}$ & $\begin{array}{l}\text { Powder fully } \\
\text { evenly } \\
\text { spread }\end{array}$ & $\begin{array}{l}\text { Powder } \\
\text { fully } \\
\text { spread }\end{array}$ & $\begin{array}{l}\text { Powder fully } \\
\text { evenly } \\
\text { spread }\end{array}$ & $\begin{array}{l}\text { Powder not } \\
\text { fully } \\
\text { spread }\end{array}$ & $\begin{array}{l}\text { Powder not } \\
\text { fully } \\
\text { spread }\end{array}$ & $\begin{array}{l}\text { Small amount of } \\
\text { powder not } \\
\text { spread }\end{array}$ \\
\hline
\end{tabular}

space due to the possibility of transferring the explosion from its interior to the environment.

The test procedure, carried out in a chamber with a capacity of $1.3 \mathrm{~m}^{3}$ (Fig. 2a), consisted of spreading a certain amount of combustible dust for various spreading air pressures and various spreading times. Each process was filmed through a special plexiglas plate (acting as an outer cover for the explosive chamber) and then analysed for the quality of the dust-air mixture obtained. Table 1 below presents examples of tested parameters for several selected samples and comments related to a given sample. The procedure of the selected spreading process corresponding to test 5 is shown in Fig. $2 b$.

After analysing the results of the spreading process, the following spreading parameters were selected to guarantee proper quality of the air-dust mixture: a spreading pressure of $10 \mathrm{bar}$ and a spreading time of about $150 \mathrm{~ms}$ (for such parameters, the spreading is even and all the supplied dust is used). Ignition tests were carried out in the test chamber for the selected spreading parameters using a $2 \mathrm{~kJ}$ energy primer for several selected ignition points and ignition delay times relative to the end of the atomization process. Based on the tests it was found that the initial should be placed approx. $0.30-0.35 \mathrm{~m}$ above the cup, and the ignition delay in relation to the end of the spreading process should be approx. 30-40 ms.

Before checking the correct operation of the explosion suppression system with a $2 \mathrm{dm}^{3}$ fire extinguisher, the initial tests were carried out on the suppression system in the $1.3 \mathrm{~m}^{3}$ explosion chamber. They consisted in checking the correctness of all recorded signals.

A signal from a pressure sensor was used to activate the system. $250 \mathrm{~g}$ of corn starch was used throughout the chamber to generate an explosion inside the test chamber. The starch spreading time was $570 \mathrm{~ms}$, while ignition was initiated after the end of spraying, i.e. within $570 \mathrm{~ms}$. A $2 \mathrm{~kJ}$ chemical primer was used as the initiator of the test explosion. It was found that all the signals were correctly 

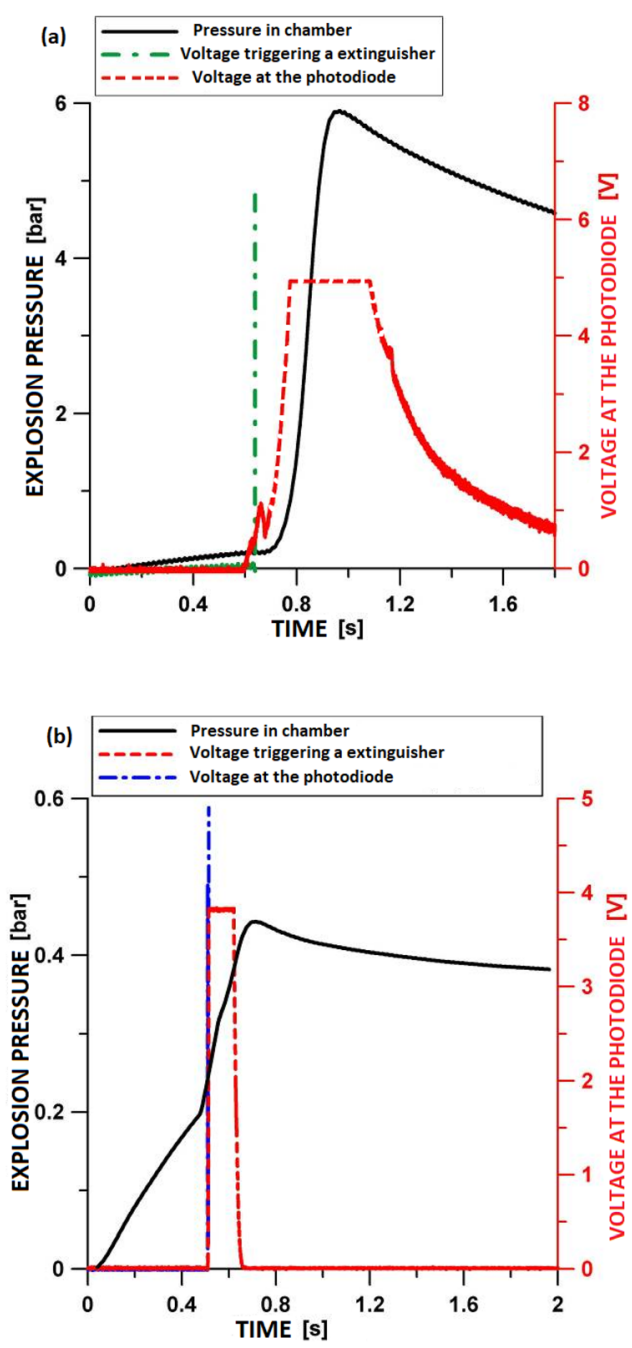

Fig. 3 Pressures in the explosion chamber: a without suppression of explosion and $\mathbf{b}$ during suppression of explosion test

recorded and the voltage activating the fire extinguisher appeared at the right time (Fig. 3a).

After testing the activation system and recording the signals, tests were carried out to check the correct operation of the explosion suppression system with a $2 \mathrm{dm}^{3}$ fire extinguisher. The settings of all parameters were the same as for the test sample. The recorded parameters are shown in Fig. 3b. As you can see from the pressure in the test chamber, the system operated very effectively to suppress the developing explosion. Maximum overpressure in the explosion chamber was 0.48 bar. It should be noted that the actual threshold for opening the fire extinguisher was very small and was around 0.03 bar. It can be stated that the explosion suppression process was very quick-the actual increase in explosion pressure inside the test chamber amounted to approx. 0.14 bar.
A high pressure fire extinguisher with a capacity of $10 \mathrm{dm}^{3}$, similar in design to a $2 \mathrm{dm}^{3}$ fire extinguisher, was tested in a $5 \mathrm{~m}^{3}$ test chamber.

The test chamber had a cylindrical shape and was equipped with a flammable dust spreading system, ignition system and pressure sensors allowing for continuous pressure recording and enabling the system to activate with a corresponding increase in overpressure. The source of ignition were two chemical primers with an energy of $10 \mathrm{~kJ}$ each. The combustible dust was corn starch for which the maximum explosion pressure is $p_{\max }=9.6 \mathrm{bar}$ and the explosion index $K_{\mathrm{st}}=175 \mathrm{bar} \mathrm{m} / \mathrm{s}$. It is highly explosive dust because the volatile matter content is $95.90 \%$ and the ash content only $0.03 \%$. The dust was relatively fine, with a grain diameter $<75 \mu \mathrm{m}$. The dust concentration was $C \mathrm{n} \cong 480 \mathrm{~kg} / \mathrm{m}^{3}$.

Sample results of tests on the explosion suppression process using extinguishing powder and water as suppressing material are shown in Fig. 4a, b. In both cases, $130 \mathrm{~g}$ of powder were used. As it can be seen, both the extinguishing powder and water effectively suppressed the explosion. This is even more important because only $3300 \mathrm{~g}$ of suppressive material was used to suppress the explosion, which gives $660 \mathrm{~g} / \mathrm{m}^{3}$ of protected space.

\section{Gas tests of high-pressure extinguisher}

For tests using the mixture of air and methane, a high pressure extinguisher with a capacity of $5 \mathrm{dm}^{3}$ and a test chamber with a capacity of $1.3 \mathrm{~m}^{3}$ were used.

During the tests, a P-200 powder charge of $90 \mathrm{~g}$ containing 3 initiating primers with an energy of $5 \mathrm{~kJ}$ each was used to disperse the extinguishing material from the fire extinguisher. The charge was placed inside the fire extinguisher in a perforated combustion chamber.

After filling the $1.3 \mathrm{~m}^{3}$ explosion chamber with a given gas mixture, an explosion was initiated using a $2 \mathrm{~kJ}$ chemical ignition primer located in the middle of the explosion chamber. The explosion pressure in the chamber was measured using a pressure sensor. The signal from this sensor was also used to start the suppression system when the pressure in the explosion chamber exceeded the set value.

The suppression system could also be activated by a signal from a photodiode reacting to the developing explosion. The pressure inside the fire extinguisher cylinder was also measured by a pressure sensor to better recognize the phenomena occurring in the fire extinguisher itself and to estimate the time of emptying the fire extinguisher powder. The extinguishing agent used was a typical powder consisting mainly of sodium bicarbonate $\left(\mathrm{NaHCO}_{3}\right)$. 

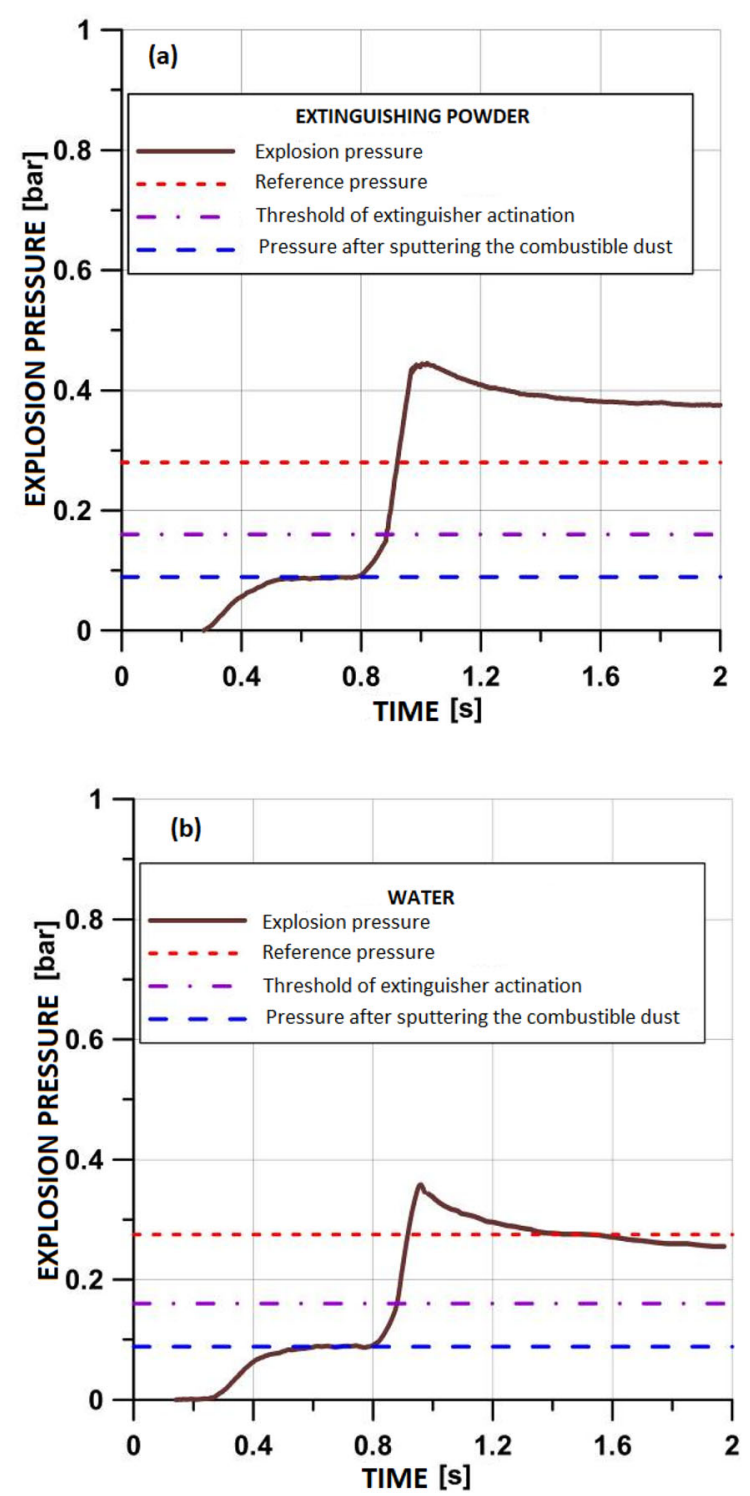

Fig. 4 Explosion pressure inside the chamber in the case of using extinguishing powder (a) and water (b)

The first tests of explosion suppression efficiency were carried out for a methane-air mixture with a methane concentration of $7.5 \%$ and $8.5 \%$. The process of the nonsuppressed explosion for a $7.5 \%$ mixture in a $1.3 \mathrm{~m}^{3}$ test chamber is shown in Fig. 5a. As you can see, the explosion overpressure for this mixture is about 5.9 bar, and the explosion pressure increase rate $\mathrm{d} p / \mathrm{d} t \sim 76 \mathrm{bar} / \mathrm{s}$, hence the deflagration index $K_{\mathrm{G}} \sim 85 \mathrm{bar} \mathrm{m} / \mathrm{s}$. The explosion overpressure for the $8.5 \%$ mixture, shown in Fig. $5 \mathrm{~b}$, is almost $7 \mathrm{bar}$, and the explosion pressure increase rate $\mathrm{d} p /$ $\mathrm{d} t \sim 90 \mathrm{bar} / \mathrm{s}$, hence the deflagration index $K_{\mathrm{G}} \sim 100$ bar $\mathrm{m} / \mathrm{s}$.

Then the test consisting in initiating and suppressing the explosion of a selected mixture with a concentration of
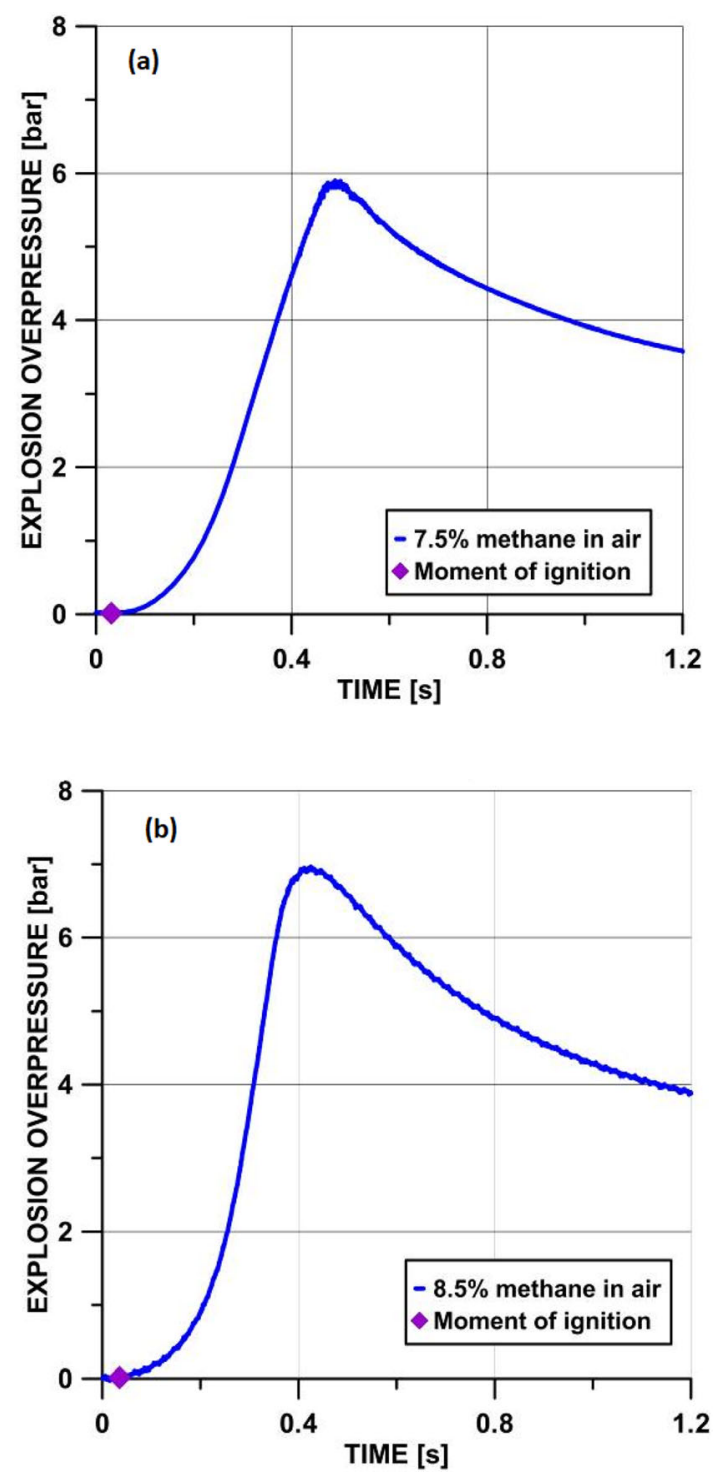

Fig. 5 Time process of explosion pressure in air-methane mixture of the following concentration: a $7.5 \% \mathrm{CH}_{4}$ and b $8.5 \% \mathrm{CH}_{4}$

$\mathrm{CH}_{4}$ equal to $7.5 \%$ was carried out. $1.7 \mathrm{~kg}$ of extinguishing powder was used for this purpose. The activation signal level from the photodiode was assumed to be $0.3 \mathrm{~V}$. Time process of the recorded parameters is shown in Fig. 6a.

As it can be seen from the pressure in the test chamber, the system operated very effectively to suppress the developing explosion. The explosion overpressure in the chamber was approx. 0.26 bar. After deducting the pressure increase in the chamber caused by the gases from the fire extinguisher (in this case about 0.2 bar), it can be assumed that the overpressure of the suppressed explosion did not exceed 0.06 bar. Figure $6 \mathrm{a}$ also shows (for the same time coordinate as the explosion pressure curve in the test 

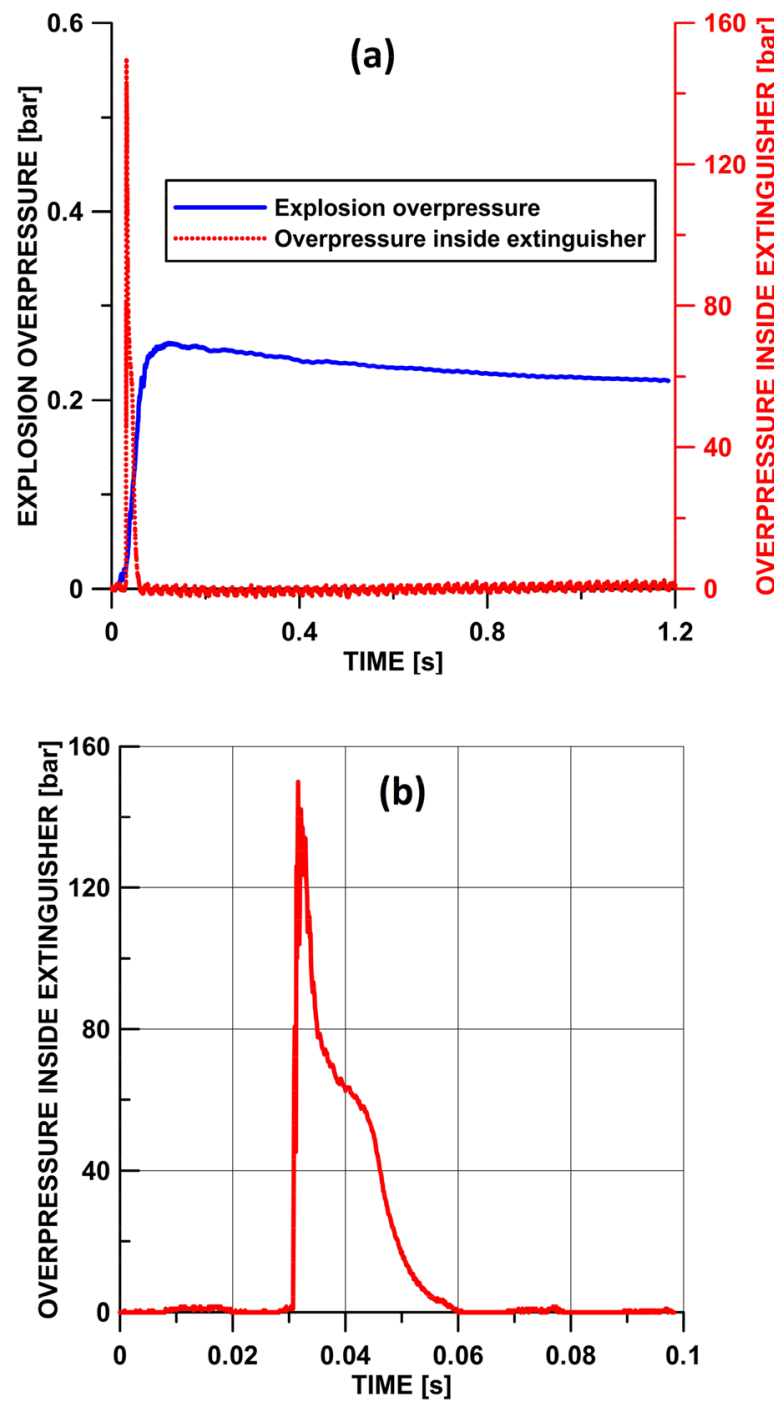

Fig. 6 Pressure waveforms recorded during the explosion suppression test ( $7.5 \% \mathrm{CH}_{4}$, signal level from the $0.3 \mathrm{~V}$ photodiode): $\mathbf{a}$ in the explosion chamber and in the fire extinguisher, $\mathbf{b}$ in the fire extinguisher

chamber) the pressure curve during the powder charge explosion inside the fire extinguisher.

The maximum pressure in the fire extinguisher was approx. 150 bar. It can be seen that the pressure inside the fire extinguisher reaches its maximum when the pressure in the test chamber is about 0.02 bar, which can be taken as the actual pressure threshold for the fire extinguisher opening. Time process of the explosion pressure in the extinguisher during the explosion of the powder charge is shown in Fig. 6b. Based on this figure, it can be estimated that the total time to empty the fire extinguisher from the powder does not exceed $28 \mathrm{~ms}$.
Table 2 Results of gas tests of high pressure fire extinguisher

\begin{tabular}{lllll}
\hline \multirow{2}{*}{ Item } & \multicolumn{4}{l}{$\begin{array}{l}\text { Level of the photodiode signal } \\
\text { (V) }\end{array}$} \\
\cline { 2 - 5 } & 0.3 & 0.6 & 1.0 & 0.3 \\
\hline $\begin{array}{l}\text { Explosion overpressure (bar) } \\
\begin{array}{l}\text { Suppression of suppressive } \\
\quad \text { explosion (bar) }\end{array}\end{array}$ & 0.26 & 0.27 & 0.40 & 0.57 \\
$\begin{array}{l}\text { Maximum pressure in the fire } \\
\quad \text { extinguisher (bar) }\end{array}$ & 150 & 132 & 225 & 140 \\
$\begin{array}{l}\text { Fire extinguisher opening threshold } \\
\quad \text { (bar) }\end{array}$ & 0.020 & 0.028 & 0.030 & 0.020 \\
$\begin{array}{l}\text { Fire extinguisher emptying time } \\
\quad(m s)\end{array}$ & 28 & 24 & 26 & 30 \\
$\begin{array}{l}\text { Methane concentration in air (\%) } \\
\text { Deflagration index (bar m/s) }\end{array}$ & 7.5 & & & 8.5 \\
\hline
\end{tabular}

Further tests verified the impact of explosion intensity on the efficiency of the explosion suppression system. Table 2 presents the test results.

The tests showed that the high-pressure fire extinguisher of the proposed design can be used in building active systems for suppressing industrial explosions not only in the suppression of explosions of dust-air mixtures but also in the case of methane-air mixtures.

\section{Testing the active system for suppressing the explosion}

Based on high pressure extinguishers with a capacity of $2 \mathrm{dm}^{3}$, the active dust suppression system was built on a dry bag dust collector (Fig. 7a), while $10 \mathrm{dm}^{3}$ extinguishers were installed in the experimental adit (Fig. 7b), in which the methane-air mixture was present (Bałaga 2015, Szkudlarek 2014).

The tests had to demonstrate the correctness and effectiveness of the active explosion suppression system in conditions similar to real ones. It was necessary to check whether the suggested solutions and the suggested number of extinguishers with extinguishing powder and the place of their installation as well as the suggested number of photo-optical sensors and the place of their installation as well as the suggested control system supervising the explosion safety in a satisfactory way enable fast and reliable suppression of a real explosion initiated in a specified work space.

The process of the active explosion suppression system operation in the dry dust collector was recorded using three cameras A, B and C (Fig. 8). The first visible traces of the extinguishing system activation can be seen a photo in Fig. 8a within $8 \mathrm{~ms}$, while in the photo with a time of $16 \mathrm{~ms}$, the particles of extinguishing dust getting through 

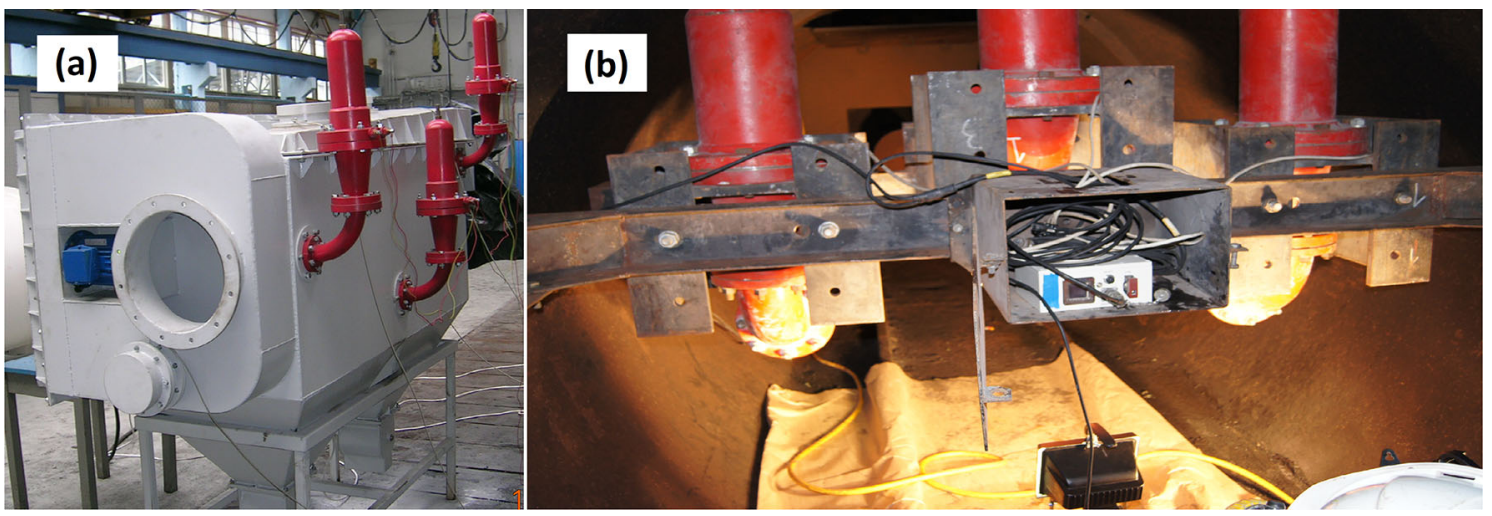

Fig. 7 Test stands for the active explosion suppression system built on the dry bag dust collector (a) and in the experimental adit (b)

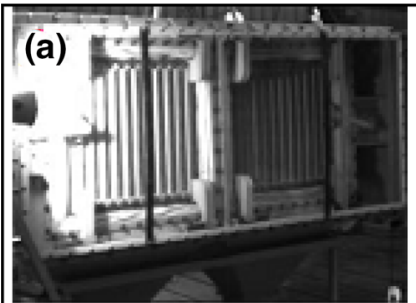

8

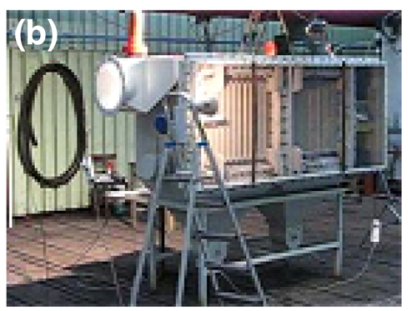

0

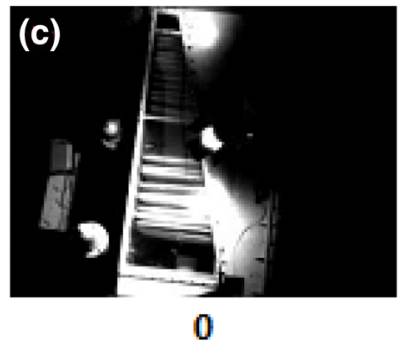

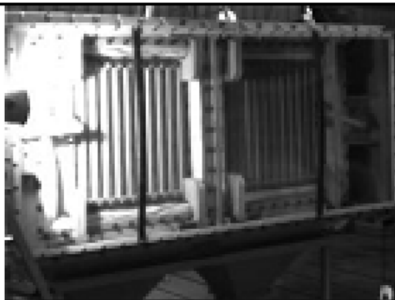

16

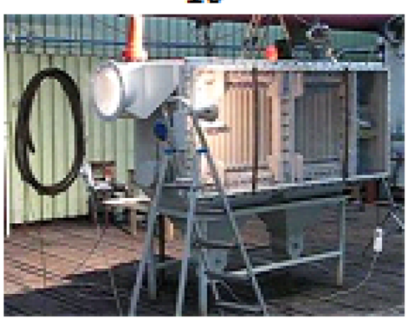

16.7

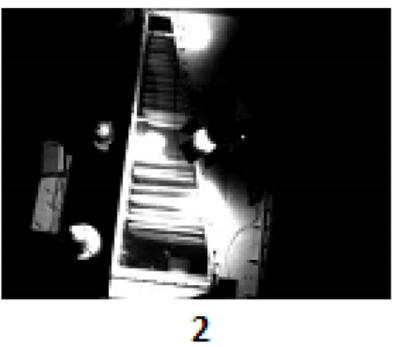

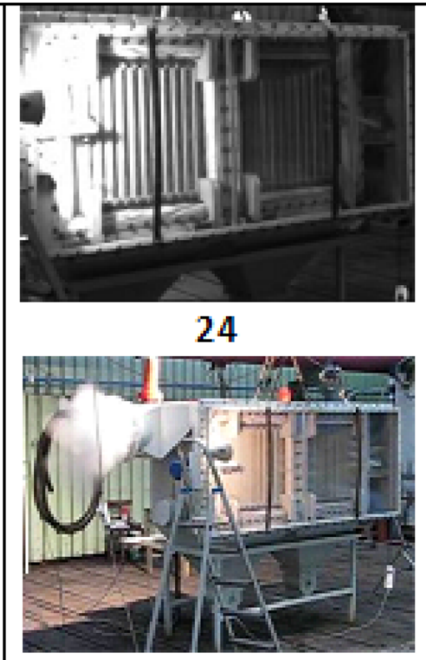

33.3

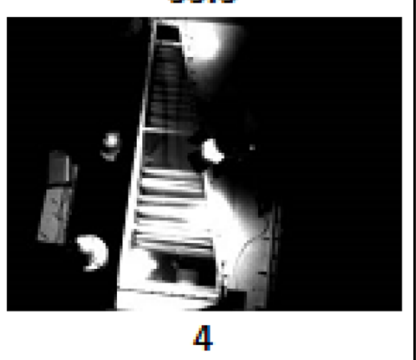

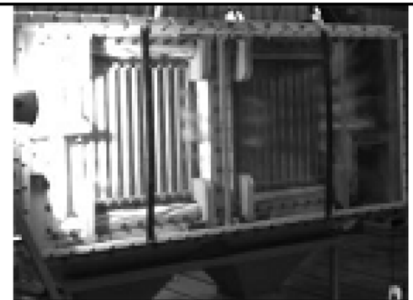

32
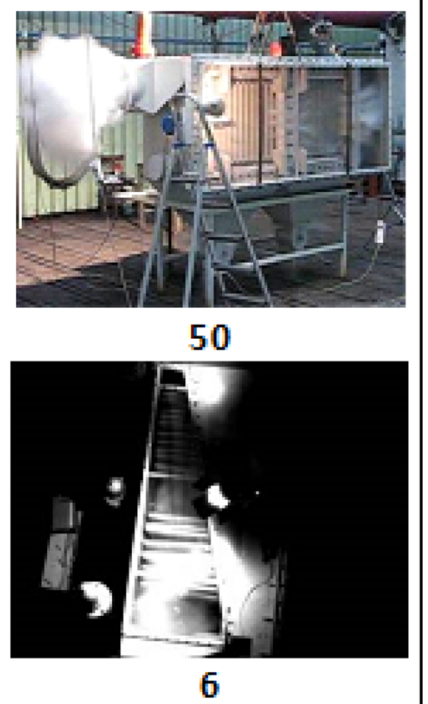

Fig. 8 Photos from explosion suppression process recorded through: a, b side wall; $\mathbf{c}$ upper wall of dust collector

the filters are clearly visible. Figure $8 \mathrm{~b}$ shows that when the extinguishing system operates, a cloud of spread extinguishing powder appears almost immediately at the entrance to the dry dust collector. Estimation of the time of appearance of a spray cloud of extinguishing powder can be approximated by comparing Fig. $8 \mathrm{a}-\mathrm{c}$. It can be seen that the moment of extinguishing powder spraying shown in Fig. 8a in the photo with a time of $32 \mathrm{~ms}$, approximately corresponds to the duration of the extinguishing powder spreading process shown in Fig. $8 \mathrm{~b}$ in the photo with a time of $33.3 \mathrm{~ms}$. As the extinguishing powder appears at the dust collector inlet after approx. $16.7 \mathrm{~ms}$ (Fig. 8b) and based on the stages of the process development shown in Fig. 8a, c, it can be assumed that the extinguishing system started operating for a time of approx. $4 \mathrm{~ms}$-i.e. extinguishing powder appears at the inlet to the dust collector approximately $12.7 \mathrm{~ms}$ from the moment the extinguishing system is activated. It proves that the extinguishing powder fills the dust collector interior very quickly and quickly escapes to the outside, creating a thick cover preventing any possible escaping the flame from the inside of the dust collector to the outside. 
As a result of the initiated explosion, an active damping system was activated, activated by a signal generated by photodiodes placed inside the dust collector. Full development of the explosion was limited in the a result of immediate operation of the system. The explosion suppression was so quick that no damage to the dust collector structure was observed. The fact that the explosion was initiated was testified, among others traces of combustion visible on the surface of the filter bags. It was found that all fire extinguishers were fully opened and the powder was completely discharged from the fire extinguishers. The control system also worked correctly.

Pilot tests of the explosion suppression system for larger volumes were carried out in the experimental adit. The purpose of this research was to observe the phenomenon of explosion and the process of its extinguishing. This process could be observed thanks to the cameras installed. In addition, the adit had side glazed openings through which one could observe the extent of the flame formed during the explosion. An example of recording a picture from the inside of an adit is shown in Fig. 9, which shows effective suppression of an explosion. At the same time, observation of the lateral holes did not reveal the flame being transferred outside the separated explosion chamber.

Tests in the experimental adit of length $40 \mathrm{~m}$ were carried out to determine amount of extinguishing powder required for a given volume of the protected area. In the tests, position of initiator to ignite air-methane mixture and its distance from the extinguishing system, in relation to the experimental working, were recreated. Volume of the protected area changed at the same amount of extinguishing powder.

During visual inspection of the extinguishing system just after the test, no damages to the structure, detection circuits and the power supply system were found. The detection system cooperated properly with the release system of extinguishers - spraying the extinguishing powder started within less than $4 \mathrm{~ms}$ what means that detection time of explosion was below $1 \mathrm{~ms}$.
The suppressing system enables to stop explosion of methane-air mixture for methane concentration below $5 \%$ under condition that concentration of extinguishing powder is over $0.7 \mathrm{~kg} / \mathrm{m}^{3}$ of the protected space. For highly dynamic explosions, where methane concentration is over $7 \%$, higher concentration of extinguishing powder, over $1.2 \mathrm{~kg} / \mathrm{m}^{3}$, is required.

The tests enabled to determine the minimum values of technical parameters of the explosion suppressing system:

(1) amount of extinguishing powder per $\mathrm{m}^{3}$ of protected space should be min. $1.1 \mathrm{~kg}$,

(2) distance from the suppressing system to the potential source of ignition should not be greater than $4.5 \mathrm{~m}$, (3) distance of the detection system from the expected place of ignition should be less than $6 \mathrm{~m}$ (without impact on the detector sensitivity to neglectable radiation spectrum e.g. light of lamp, sparks, etc.).

Besides, subassemblies of the explosion suppressing system should have the following properties due to the specific work environment (dangerous atmosphere spatial confinement in result of machines and equipment installation):

(1) should be shock resistant and dirt resistant (especially flame and explosion detectors),

(2) possibility of installation on the machine or in the operational area (especially extinguishers which are of bigger size),

(3) should have special nozzles to spread the powder evenly in the roadway cross-section,

(4) range of sensors detection should be determined in such a way that the sensors react only on those phenomena that have to be controlled. Only explosions close to the roadheader, caused by operation of cutter head, should be detected and not fires out of the cutting area.

Example of a possible application of the suppressing system on a working machine used in the mining industry

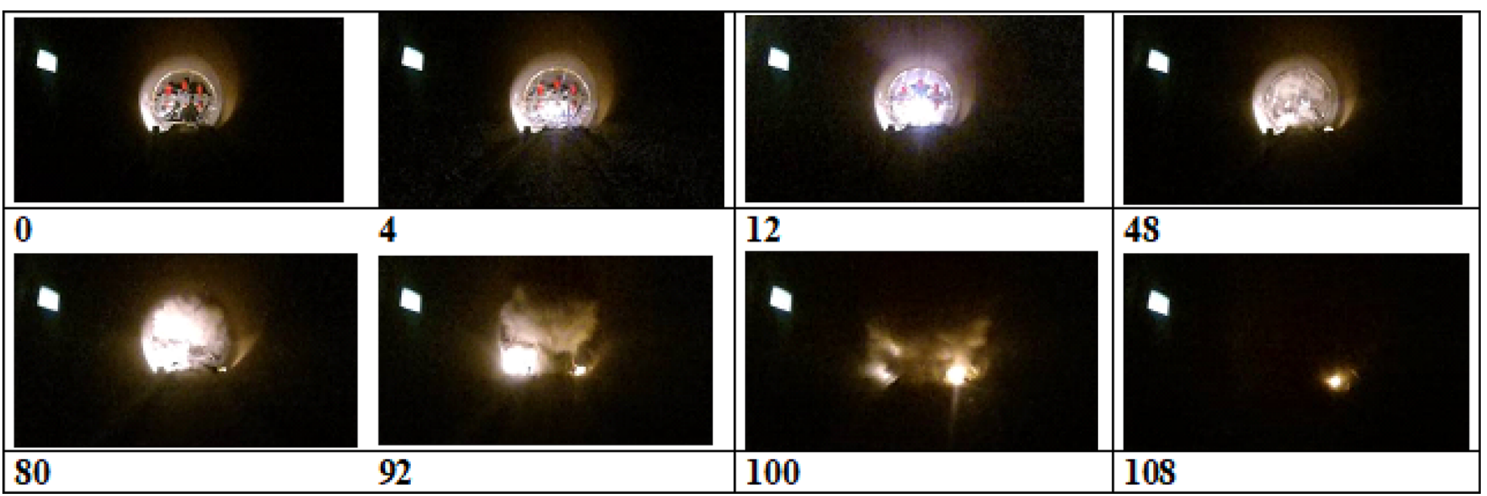

Fig. 9 Photos of the explosion suppression process 

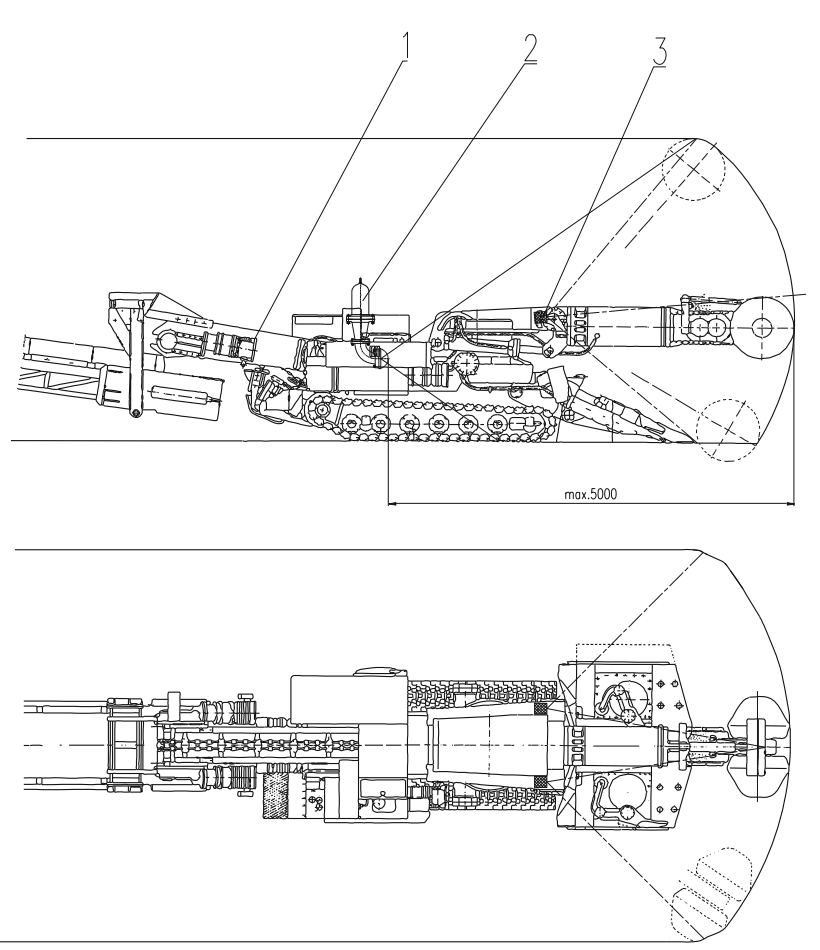

Fig. 10 Layout of installation of the suppressing system on roadheader: (1-roadheader; 2-set of extinguishers; 3-detection system)

is presented (Fig. 10). It is a roadheader used to develop underground workings of a specific cross-sectional shape. Defining the shape is programmable, what means that this machine can work automatically.

Flow rate and time of emptying the extinguishing agent out of the extinguisher depend on the geometrical features of the roadheader. Due to this, especially the following parameters should be taken into account:

(1) distance from cutter head,

(2) radial dimensions of roadway cross-section,

(3) direction of flow of extinguishing agent in relation to roadheader arm axis.

\section{Conclusions}

Explosion suppression system is a response for the requirements of Machinery Directive and ATEX Directive and other harmonized regulations for the integrated explosion-proof protection system. Designed and tested explosion suppression system meets requirements of the protective systems minimizing negative impact of explosion. Detailed specification of conditions, in which the system will operate i.e. the volume of protected area and spatial arrangements of machine and equipment is required to run the system properly.

The positive results of stand tests (recreating the real conditions) of the system encouraged to disseminate the developed solution among users to enable them to increase available protective measures improving the work safety in areas of increased exposure to gas and dust hazard.

The system can be efficient for a specified scenario of working machine operation.

Acknowledgements The project was supported by the Research Fund for Coal and Steel (Project MINFIREX No RFCR-CT-20100005).

\section{Compliance with ethical standards}

Conflict of interest The authors declare that there is no conflict of interest.

Open Access This article is licensed under a Creative Commons Attribution 4.0 International License, which permits use, sharing, adaptation, distribution and reproduction in any medium or format, as long as you give appropriate credit to the original author(s) and the source, provide a link to the Creative Commons licence, and indicate if changes were made. The images or other third party material in this article are included in the article's Creative Commons licence, unless indicated otherwise in a credit line to the material. If material is not included in the article's Creative Commons licence and your intended use is not permitted by statutory regulation or exceeds the permitted use, you will need to obtain permission directly from the copyright holder. To view a copy of this licence, visit http://creativecommons. org/licenses/by/4.0/.

\section{References}

Bałaga D, Jedziniak M, Kalita M, Siegmund M, Szkudlarek Z (2015) Metody i środki zwalczania zagrożeń pyłowych i metanowych w górnictwie węglowym [Methods and measures to combat dust and methane hazards in coal mining]. Maszyny Górnicze 3:68-81 (in Polish)

Bochorishvili N, Chikhradze N, Mataradze E, Akhvlediani I, Chikhradze M, Krauthammer T (2015) New suppression system of methane explosion in coal mines. Procedia Earth Planet Sci 15:720-724. https://doi.org/10.1016/j.proeps.2015.08.102

Cao X, Ren J, Zhou Y, Wang Q, Gao X, Bi M (2015) Suppression of methane/air explosion by ultrafine water mist containing sodium chloride additive. J Hazard Mater 285:311-318. https://doi.org/ 10.1016/j.jhazmat.2014.11.016

du Plessis JJL (2015) Active explosion barrier performance against methane and coal dust explosions. Int J Coal Sci Technol 2(4):261-268. https://doi.org/10.1007/s40789-015-0097-7

Gieras M, Klemens R (2012) Effectiveness of an active dust and gas explosion suppression system. J Power Technol 92(1):1-11

Klemens R, Gieras M, Kałużny M (2007) Dynamics of dust explosions suppression by means of extinguishing powder in various industrial conditions. $J$ Loss Prev Process Ind 20:664-674

Lesiak P, Bąk D, Małozięć D, Grabarczyk M, Kołaczkowski A (2019) Evaluation of the effectiveness of active HRD systems for dust explosion suppression in a technology demonstrator system. Saf Fire Technol 53(1):46-67 
Moore PE (1996) Suppressants for the control of industrial explosions. J Loss Prev Process Ind 9(1):119-123. https://doi.org/10. 1016/0950-4230(95)00045-3

Oleszczak P, Gieras M, Kałużny M, Klemens R (2007) Dust explosions suppression by means of water spray and suppressing powder. Novel extinguisher design. In: Proceedings of the 5th international seminar on fire and explosion hazards, Edinburgh, UK, 23-27 April 2007

Pei B, Yang Y, Li J, Yu M (2018) Experimental study on suppression effect of inter gas two fluid water mist system on methane explosion. Procedia Eng 211:565-574

Pei B, Wei S, Chen L, Pan R, Yu M, Jing G (2019) Synergistic inhibition effect on the self-acceleration characteristics in the initial stage of methane/air explosion by $\mathrm{CO}_{2}$ and ultrafine water mist. R Soc Chem Adv 9:13940-13948. https://doi.org/10.1039/ C9RA01148J
Späth H, Yu AS, Dewen N (2011) A New dimension in coal mine safety: ExploSpot, active explosion suppression technology. Procedia Eng 26:2191-2198

Szkudlarek Z (2014) Badania skuteczności tłumienia wybuchów metanu [Studies on the effectiveness of methane explosion suppression]. Maszyny Górnicze 1:36-44 (in Polish)

Szkudlarek Z, Klemens R, Gieras M (2014) Suppression of methane explosion with the use of the high-pressure extinguisher. Przegląd Górniczy 4:74-80 ( in Polish)

Wang Y, Cheng Y, Yu M, Li Y, Cao J, Zheng L, Yi H (2017) Methane explosion suppression characteristics based on the $\mathrm{NaHCO}_{3}$ /red-mud composite powders with core-shell structure. J Hazard Mater 335(5):84-91. https://doi.org/10.1016/j.jhazmat. 2017.04.031 